\title{
Effect of low dose nebulised morphine on exercise endurance in patients with chronic lung disease
}

\author{
I H YOUNG, E DAVISKAS, V A KEENA
}

From the Department of Thoracic Medicine, Royal Prince Alfred Hospital, Camperdown, New South Wales, Australia

\begin{abstract}
Low dose nebulised morphine may relieve dyspnoea through a direct effect on lung afferent nerves. To study this further 11 adult patients with advanced chronic lung disease (FEV range 0.4-1.4 1), whose exercise endurance was limited by dyspnoea, were entered into a double blind, randomised, crossover study in which low dose morphine or a placebo was inhaled. The effects were assessed by an endurance exercise test at $80 \%$ of maximum work load. One hour after a control endurance test patients inhaled $5 \mathrm{ml}$ of morphine $1 \mathrm{mg} / \mathrm{ml}$ or isotonic saline for 12 minutes from a jet nebuliser. An endurance exercise test was repeated 15 minutes later and change in endurance time recorded. The two endurance tests were repeated on a separate day, before and after inhalation of the alternative solution. In all tests $100 \%$ oxygen was inhaled from a demand valve. The mean (SD) increase in endurance time was significantly greater after the subjects had inhaled morphine (64.6 (115) s, 35\%) than after placebo $(8.9(55) \mathrm{s}, 0.8 \% ; \mathrm{p}<0.01)$. The mean dose of morphine nebulised was $1.7(0.66) \mathrm{mg}$, giving a mean inhaled dose of about $0.6 \mathrm{mg}$, on the assumption of $30 \%$ retention of the nebulised dose by each patient. No side effects were reported. Possibly small amounts of morphine delivered to the lungs act directly on lung afferent nerves to reduce dyspnoea.
\end{abstract}

\section{Introduction}

Dyspnoea is frequently the most distressing symptom of patients with chronic lung disease. Attention should be paid to reversing the pathological process, but this is rarely possible in the advanced stages of chronic obstructive lung disease or idiopathic pulmonary fibrosis. In the last decade some workers have explored treatment strategies designed primarily to relieve dyspnoea, ${ }^{1-6}$ including the use of narcotic drugs. ${ }^{23}$ Oral and injected morphine is effective in relieving dyspnoea but the undesirable side effects of respiratory depression, nausea, constipation, and anorexia have been reported. ${ }^{23}$

We noted a beneficial effect of small doses of nebulised morphine in a patient with primary pulmonary hypertension. Since dyspnoea in this condition arises before there is any substantial derangement of lung mechanics that could load the respiratory mus-

Address for reprint requests: Dr I H Young, Department of Thoracic Medicine, Royal Prince Alfred Hospital, Camperdown, New South Wales 2050, Australia.

Accepted 6 February 1989 cles or any disturbance of arterial blood gas tensions, vagal afferent traffic from perivascular lung receptors is probably important in initiating the sensation. ${ }^{3}$ Blocking the vagus nerves by surgical section or local anaesthesia has been shown to reduce the sensation of dyspnoea in certain patients. ${ }^{7}$ Recent evidence points to endorphins in the cell bodies of peripheral nerves, and this provides the basis for possible local action of narcotic drugs on these nerves. ${ }^{8}$ The present study was designed to determine if low dose nebulised morphine has an affect on exercise endurance in patients with chronic lung disease limited by dyspnoea.

\section{Methods}

SUBJECTS

We initially studied 18 patients with a clinical diagnosis of chronic obstructive lung disease or idiopathic pulmonary fibrosis referred by physicians attending the Royal Prince Alfred Hospital. Patients with symptoms of ischaemic heart disease were excluded. We obtained informed consent to the protocol, which was approved by the Royal Prince Alfred Hospital ethics committee.

Patients were asked to perform a progressive exer- 
cise test on an electrically braked cycle ergometer, in which the load was increased $10 \mathrm{w}$ every minute, to their maximum ability while breathing $100 \%$ oxygen. At the end of the test each patient was asked his limiting symptom. Seven patients were limited by leg fatigue, dry mouth, or general fatigue, and did not participate further in the study. Eleven patients were limited by dyspnoea, defined as difficult or laboured breathing limiting the ability to exercise. Nine of these had chronic obstructive lung disease and two had idiopathic pulmonary fibrosis (table).

\section{TEST SOLUTIONS}

The test solutions were morphine sulphate, $1 \mathrm{mg} / \mathrm{ml}$ in $0.9 \%$ saline, and a placebo of $0.9 \%$ saline. They were allocated in a double blind fashion in random order by the hospital pharmacist.

\section{EXERCISE PROTOCOL}

The initial progressive exercise test was used to determine those patients whose exercise capacity was limited by dyspnoea and also served to identify the maximum work load (Wmax) for each patient.

\section{STUDY DESIGN}

During each exercise test all patients breathed $100 \%$ oxygen from a demand valve through a one way Hans Rudolph exercise valve and mouthpiece, and expired minute ventilation was measured in a Tissot spirometer. Oxygen was given to reduce any drive to ventilation from the carotid bodies, which could be influenced by circulating morphine. No particular instructions were issued to the patients with the exception of having to pedal at 60 cycles/min until he or she felt the need to stop.

Each patient was studied on two or three separate days. After resting for two hours after the initial exercise test, or on a separate day, the patients

\section{Characteristics of patients studied}

\begin{tabular}{llllll}
\hline $\begin{array}{l}\text { Patient } \\
\text { No }\end{array}$ & $\begin{array}{l}\text { Age } \\
(y)\end{array}$ & Diagnosis & $\begin{array}{l}F E V, \\
(l)\end{array}$ & $\begin{array}{l}V C \\
(l)\end{array}$ & $\begin{array}{l}\text { Morphine dose } \\
\text { nebulised (mg)十 }\end{array}$ \\
\hline 1 & 58 & IPF & 1.3 & 1.4 & 0.4 \\
2 & 39 & COLD & 0.6 & 2.9 & -7 \\
3 & 43 & COLD & 0.5 & 3.0 & 2.0 \\
4 & 71 & COLD & 1.2 & 3.3 & 1.4 \\
5 & 61 & COLD & 1.2 & 2.2 & 2.8 \\
6 & 72 & IPF & 1.4 & 1.8 & 1.6 \\
7 & 74 & COLD & 0.6 & 2.0 & 2.4 \\
$8^{*}$ & 46 & COLD & 0.5 & 2.6 & 1.4 \\
9 & 72 & COLD & 1.4 & 4.0 & 1.9 \\
$10^{*}$ & 41 & COLD & 1.0 & 2.9 & 1.3 \\
11 & 66 & COLD & 0.4 & 1.1 & 1.7 \\
\hline
\end{tabular}

IPF-Idiopathic pulmonary fibrosis; COLD - chronic obstructive lung disease; $F E V_{1}$ - forced expiratory volume in one second; VCvital capacity.

*Alpha, protease inhibitor deficiency.

†Delivered dose as measured by weighing the nebuliser and mask before and after the 12 minute nebulisation. performed a control endurance exercise test at $80 \%$ of Wmax and the endurance time was recorded. After at least an hour's rest each patient inhaled $5 \mathrm{ml}$ of morphine $(1 \mathrm{mg} / \mathrm{ml})$ or saline. The solutions were given in random order and double blind, a jet nebuliser (Hudson) and face mask driven by $6 \mathrm{l} / \mathrm{min}$ of oxygen being used. The median particle diameter generated by a Hudson nebuliser is $\mathbf{2 . 3}$ (geometric standard deviation 1.9) $\mu \mathrm{m}$. ${ }^{9}$ The patients breathed normally for 12 minutes from the nebuliser while sitting comfortably. The nebuliser and mask were weighed before and after the 12 minute nebulisation and the difference in grams was recorded as millilitres delivered. Fifteen minutes after completing the inhalation of nebulised solution each patient repeated the endurance exercise test at the same work load; the endurance time was recorded. The reason for stopping and any difference in sensation between control and post-solution endurance exercise tests were recorded. FEV , and vital capacity (VC) were measured before and after each exercise test with a Minato 500 Autospirometer (Minato, Osaka, Japan) while the patient was standing, and were repeated until two values were obtained which were reproducible to within $100 \mathrm{ml}$, the higher value being recorded. On a separate day, the same procedure was repeated with inhalation of the alternative solution.

\section{DATA ANALYSIS}

The paired changes in endurance time (in seconds) and in ventilation during the last minute of exercise after morphine and placebo from control values on the same day (morphine - control and placebo - control) were compared by means of a two tailed Wilcoxon signed rank test. This non-parametric test was used to avoid assumptions about the population distributions in view of the small sample size.

\section{Results}

The patients' characteristics are shown in the table. Nine of the patients had chronic obstructive lung disease, in six cases associated with a long smoking history, and two patients had idiopathic pulmonary fibrosis. Two patients had $\alpha_{1}$ protease inhibitor deficiency and one patient (No 2) had a short smoking history, accelerated development of emphysema, and airways obstruction with normal $\alpha_{1}$ antitrypsin levels. Initial values of FEV ranged from 0.4 to 1.41 and of VC from 1.1 to $4.0 \mathrm{l}$, and these did not change significantly during the study. In patient 2 the dose of morphine delivered was not measured; in the remaining 10 patients the mean dose delivered was $1.7 \mathrm{mg}$.

There was considerable variability in endurance times (fig 1), five patients increasing their time after placebo. Nine patients, however, showed a longer endurance time after morphine. The work load of 


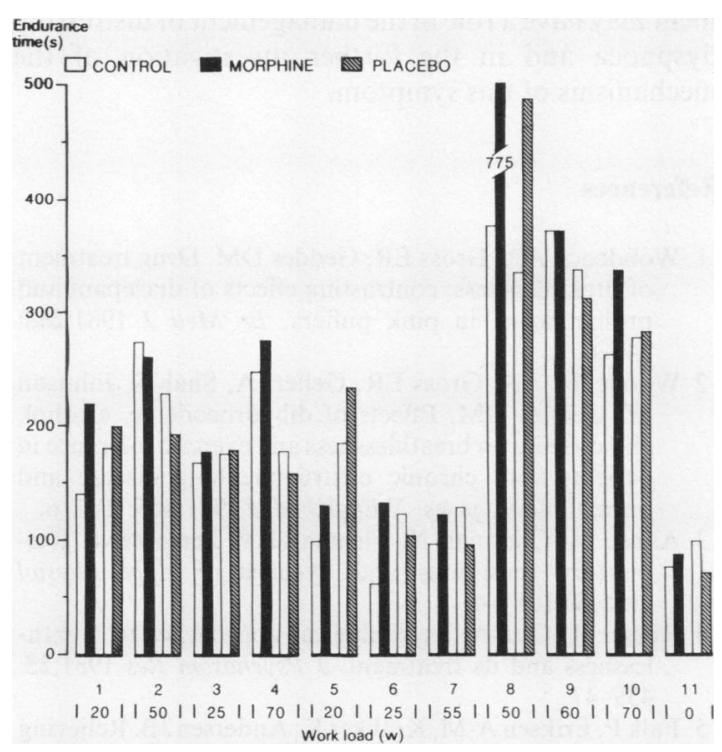

Fig 1 Exercise endurance times before (control) and after nebulised morphine and placebo for each patient. The patients' identification numbers and work loads in watts are indicated. Patient 8 exercised for 775 seconds after morphine.

patient 11 was recorded as zero as she could accomplish only pedalling without a load. After inhalation of morphine the mean endurance time increased from 198 to 262 seconds, and after inhalation of placebo from 204 to 213 seconds. The mean (SD) increase in endurance time was significantly greater after morphine $(64.6(115) \mathrm{s})$ than after placebo $(8.9(55) \mathrm{s}$; $\mathrm{p}<0.01$ ). Most patients reported no difference in sensation after morphine or after placebo, though three noted a "lighter" feeling in the chest during exercise after inhaling morphine. All subjects described dyspnoea as the limiting symptom after control, placebo, and morphine tests. None reported a difference in taste between the two solutions or any irritation during nebulisation. There was no significant effect of morphine on ventilation in the last minute of exercise (fig 2), the mean (SD) change being $1.4(5.2) 1 / \mathrm{min}$ after morphine and $-0.3(4.5) 1 / \mathrm{min}$ after placebo $(p>0 \cdot 1)$.

\section{Discussion}

This study was stimulated by our clinical finding that small doses of nebulised morphine improved dyspnoea at rest in a patient with advanced primary pulmonary hypertension. Another patient with a distressing chronic hyperventilation syndrome (arterial carbon dioxide tension $2.9 \mathrm{kPa}$ ), possibly due to pulmonary vasculitis, was also greatly relieved by

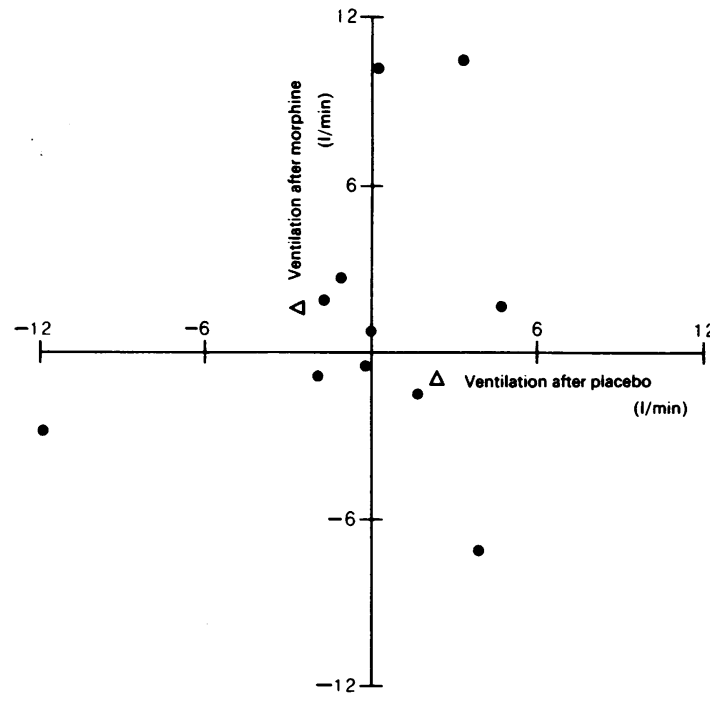

Fig 2 Change in ventilation during the last minute of exercise between the control and the placebo test plotted against the change between the control and the morphine test for each patient. A reduction in minute ventilation after morphine would be shown by a grouping of the points below and to the right of the line of identity, which would run at $45^{\circ}$ to the ordinate.

the administration of regular nebulised morphine, whereas oral codeine up to a dose of $90 \mathrm{mg}$ per day did not help. We considered that nebulised morphine might be acting on peripheral neural receptors in the lung, modulating afferent traffic, which is possibly an important contributor to the sensation of dyspnoea in such patients. ${ }^{3}$ Opioid peptide immunoreactivity has been detected in cells in the bronchial mucosa ${ }^{8}$ and in dorsal horn cells in the spinal cord. The effect of morphine did not appear to be dose dependent at these generally small dose levels (mean nebulised dose 1.7 (SD 0.66) $\mathrm{mg}$ ). This may be appreciated by comparing the doses delivered (table) with the responses of individual patients (fig 1). Probably only a third of the nebulised dose was retained past the lips because the patients were breathing via an open face mask during the continuous nebulisation and only about one third of the breathing cycle is spent in inspiration. The small amounts of morphine actually entering the lung (considerably less than the mean $0.6 \mathrm{mg}$ retained past the lips) suggest that it may be acting locally. Alternatively, the patients may be responding to the central action of small doses absorbed from the buccal and airway mucosa. Such absorption would bypass liver metabolism, which inactivates half of the morphine passing through the portal circulation.

We removed any hypoxic stimulus to ventilation 
and dyspnoea by giving the patients $100 \%$ oxygen during the exercise tests. Other central nervous system mechanisms mediating dyspnoea could, however, be suppressed by morphine. Repeat studies using a similar dose of sublingual morphine could indicate whether these small doses are having a central effect after absorption. We must emphasise that this study protocol did not directly address the effect of nebulised morphine on dyspnoea. We elected to examine exercise endurance time after pilot studies had suggested a beneficial effect of the morphine. This measurement has the advantage of a definite end point and has clear clinical importance. We attempted to connect dyspnoea and endurance time by selecting patients whose exercise endurance appeared to be limited by breathlessness and not by peripheral muscle fatigue or other discomfort. This connection of exercise endurance with dyspnoea must, however, be regarded as tenuous and the mechanism of the increase in endurance after morphine uncertain. Measuring the relation between exercise ventilation and visual analogue scale scores would be of interest as a more direct assessment of dyspnoea. ${ }^{1011}$

In a recent review ${ }^{12}$ Stark distinguishes between agents causing a fall in ventilation and breathlessness without a change in the relation between the two (type I response) and agents causing a reduction in breathlessness at a given level of ventilation (type II response). We did not measure breathlessness in these experiments and each exercise test was performed at a single work load rather than with a progressive increase in load, making it difficult to determine the type of response by the above criteria. The lack of an effect of the nebulised morphine on exercise ventilation, however, suggests that it was having a type II effect. The factors limiting exercise endurance in our selected group of patients were undoubtedly complex and it is not surprising that the responses to morphine were variable. Nevertheless, the statistically significant response of the group and the complete lack of reported side effects in other patients given nebulised morphine over longer periods suggest that this treat- ment may have a role in the management of distressing dyspnoea and in the further investigation of the mechanisms of this symptom.

\section{References}

1 Woodcock AA, Gross ER, Geddes DM. Drug treatment of breathlessness: contrasting effects of diazepam and promethazine in pink puffers. $\mathrm{Br}$ Med $J$ 1981;283: 343-6.

2 Woodcock AA, Gross ER, Gellert A, Shah S, Johnson M, Geddes DM. Effects of dihydrocodeine, alcohol, and caffeine on breathlessness and exercise tolerance in patients with chronic obstructive lung disease and normal blood gases. $N$ Engl J Med 1981;305:1611-6.

3 Altose M, Cherniak N, Fishman AP. Perspective. Respiratory sensations and dyspnea. J Appl Physiol 1985;58:1051-4.

4 Rosser R, Guz A. Psychological approaches to breathlessness and its treatment. J Psychosom Res 1981;25: 439-47.

5 Falk P, Eriksen A-M, Kolliker K, Andersen JB. Relieving dyspnoea with an inexpensive and simple method in patients with severe chronic airflow limitation. Eur $J$ Respir Dis 1985;66:181-6.

6 Woodcock AA, Gross ER, Geddes DM. Oxygen relieves breathlessness in "pink puffers." Lancet 1981;i:907-9.

7 Stark RD, Guz A. Dyspnoea: symptoms. Runcorn: Pharmaceuticals Division, ICI, 1984.

8 Bostwick DG, Null WE, Holmes D, Weber E, Barchas JD, Bensch KG. Expression of opioid peptides in tumours. $N$ Engl J Med 1987;317:1439-43.

9 Sterk PJ, Plomp A, van de Vate JF, Quanjer PH. Physical properties of aerosols produced by several jet and ultrasonic nebulizers. Bull Eur Physiopathol Respir 1984;20:65-72.

10 Stark RD, Gambles SA, Chatterjee SS. An exercise test to assess clinical dyspnoea: estimation of reproducibility and sensitivity. Br J Dis Chest 1982;76:269-78.

11 Leblanc P, Bowie DM, Summers E, Jones NL, Killian $\mathrm{KJ}$. Breathlessness and exercise in patients with cardiorespiratory disease. Am Rev Respir Dis 1986;33: 21-5.

12 Stark RD. Dyspnoea: assessment and pharmacological manipulation. Eur Respir J 1988;1:280-7. 